Contraimágenes para una California alternativa...

\title{
CONTRAIMÁGENES PARA UNA CALIFORNIA ALTERNATIVA: LOS DIGGERS, BRUCE NAUMAN Y TERRY RILEY EN SAN FRANCISCO ${ }^{1}$
}

\author{
Óskar DÍEZ \\ I. E. S. Elaios (Zaragoza)
}

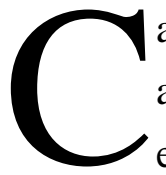

alifornia, años 60. El estado más próspero de la nación en el momento de apogeo del sueño americano. No es un paisaje que culturalmente nos resulte extraño; disponemos de una luminosa imagen del estado californiano acompañada por el sonido de los Beach Boys, de The Mamas \& The Papas (California Dreamin' ) y todos los tópicos que evocan soles radiantes sobre cielos azules, playas rebosantes de belleza y el verano sin fin de los surfistas. California es, al tiempo, sinónimo de cine; allí está Hollywood, La fábrica de los sueños, el formidable complejo encargado de transmitir al planeta el mensaje del American Way of Life...

Los 60 son además la década del rock -los Doors, los Jefferson Airplane o los Grateful Dead, por citar sólo tres grupos californianos- y del Pop art, Andy Warhol, Lichtenstein, Wesselmann, Oldenburg. Este movimiento confirma a Nueva York como capital artística del mundo. Son elementos que, en su conjunto, ejemplifican la iniciativa cultural norteamericana, la cual -tras esos epígonos de la vanguardia europea que acaban por ser los artistas de la action painting, del expresionismo abstracto o del colour field painting-disuelve el elitismo y se abre a las masas y a la cultura popular.

En plena guerra fría, los EE. UU. tratan de irradiar al mundo la imagen de una tranquila serenidad en el camino a una prosperidad sin límites, la idea de un país triunfante, joven y fuerte -the home of the braves- que esparce generosamente su modelo sobre el mundo libre.

Sin embargo, se trata de un paisaje luminoso no exento de sombras. El 22 de noviembre de 1963 se ha producido el asesinato del presidente Kennedy, cuya elección

\footnotetext{
${ }^{1}$ Una versión muy abreviada de este artículo ha sido publicada en el número 23 de la revista Laberintos (Zaragoza, mayo 2011) con el título "Los Diggers: el lado anarca de la California hippie".
} 
había generado grandes expectativas de cambio. Pervive una terrible y apenas disimulada discriminación racial que es percibida, cada vez más, como intolerablemente contradictoria con los principios en teoría representados por el sistema. En California, en 1965, los disturbios raciales en el barrio de Watts, el guetto negro de Los Ángeles dejan decenas de muertos, heridos y detenidos. No serán ni los primeros ni los últimos estallidos de tensión racial en la década.

En todo caso, después de que la crisis de los misiles de Cuba dé paso al periodo de la "coexistencia pacífica" entre los dos bloques antagónicos, parece que el poder de las fuerzas más conservadoras de ambos lados del telón de acero está firmemente consolidado. Apenas nada -más allá de la anomalía cubana- parece inquietar a las superpotencias. No cabe predecir horizonte revolucionario alguno; no, desde luego, en el próspero occidente; más improbable todavía en el otro lado, el tutelado por la Unión Soviética. Pero estallará el 68, la última revolución de occidente, revolución que ha comenzado años antes, en la costa oeste norteamericana.

Este artículo pretende dar unas pinceladas sobre tres contraimágenes, presencias -diversas entre sí- que contradicen o, al menos, difieren, del modelo antes citado y que confluyen -a veces en el mismo instante y en los mismos lugares- en esa California de la segunda mitad de los años 60, y más concretamente en el área de la bahía de San Francisco: los Diggers - por un lado- encarnando, desde su experiencia en el barrio de Haight Ashbury, el lado anarca de la California hippie. En segundo lugar, Terry Riley -pionero de la música electrónica- iniciando el desarrollo de la corriente del minimalismo musical a partir de la escena alternativa de San Francisco. Finamente, un jovencísimo Bruce Nauman, artista pionero del arte conceptual y del videoarte, acuñando en esos mismos meses las líneas fundamentales de lo que será su labor creativa. Como tres cobayas recorriendo un laberinto, tal vez no llegan nunca a cruzarse pero comparten un mismo espíritu de innovación y transformación social o estética en una ciudad que por unos meses es el centro del mundo.

En los años cincuenta, particularmente en los EE. UU., se asiste al nacimiento de una nueva forma de subjetivación -la juventud-, proceso que se consolida en los años sesenta, constituyendo un acontecimiento histórico de primer orden. Este proceso es paralelo a la prolongación generalizada de los años de estudio, a la masificación de las universidades y al consiguiente retraso de la edad de incorporación al mercado laboral. A finales de los años 60 casi la mitad de la población norteamericana tiene menos de 25 años. Con tiempo libre y con dinero en el bolsillo, la triunfante sociedad de consumo va a encontrar en este nuevo sujeto -cuyos perfiles contribuye decisivamente a dibujar- un 
nuevo e inexplorado mercado que satisfacer. Es el momento del surgimiento de un lenguaje, una música -el rock-, un cine y un estilo de vida propios de los teenagers ${ }^{2}$.

Dos aspectos confirman el carácter novedoso del espacio de potencial libertad abierto a esta nueva generación de jóvenes. En primer lugar, la difusión de la píldora anticonceptiva que desde principios de la década sienta las bases de la liberación sexual, abriendo la posibilidad de redefinir las relaciones personales y dando paso a la emancipación del esquema reproductivo e institucional representado por el modelo de familia tradicional. En segundo lugar, la creciente popularización de drogas como el LSD -legal hasta octubre del 66 en EE. UU.-, que contribuye a fomentar actitudes mentales y vitales muy diferentes a las convencionales. No sólo la sociedad y las relaciones que en ella se producen se transforman sino que es la propia percepción -abiertas sus puertas - la que se modifica y, con ello, la visión del mundo, de lo que sea la individualidad y de la vida entera. A partir de su consumo y de la (contra)cultura que se genera en torno a ella -música, espacios, relaciones-, surge el movimiento psicodélico.

Sin embargo, impermeable a las transformaciones, la sociedad norteamericana continúa siendo profundamente conservadora en lo político y en lo moral ${ }^{3}$. Las contradicciones se acentúan.

El Movimiento por los Derechos Civiles, creado a mediados de los años cincuenta para reivindicar el fin de la segregación de la población negra, especialmente en los estados sureños, alcanza su momento álgido en agosto de 1963 con la marcha sobre Washington, donde miles de manifestantes escuchan a Martin Luther King el célebre discurso que comienza con la frase «I have a dream»... Hay una América -masiva y, hasta entonces, sin voz- que tiene un sueño distinto al oficial. Muchos jóvenes

\footnotetext{
${ }^{2}$ A este respecto parecen extraordinariamente significativas estas palabras del músico de rock Frank Zappa referidas a su juventud: «Recuerdo cuando fui a ver Blackboard Jungle (Semilla de Maldad). Cuando el título apareció en la pantalla, Bill Halley \& the Comets iniciaron "one, two, three o'clock, four óclock rock"... Era el sonido rock más fuerte que los chicos habíamos oído hasta el momento. Recuerdo mi estupor. En las habitaciones atestadas de chiquillos de toda América, los jóvenes siempre se habían reunido en torno a las viejas radios y tocadiscos baratos para escuchar la "música obscena" de su estilo de vida ("Vete a tu cuarto si quieres oír esa porquería... iy baja el volumen!"). Pero en el cine, frente a Blackboard Jungle, no podían decirte que bajaras el volumen. [...] Aun sin tener en cuenta el desarrollo del argumento (que al final veía victoriosos a los adultos), representó una extraña forma de "aval" de la causa juvenil: "Han hecho un film sobre nosotros; por consiguiente existimos"» (Jiménez, 2000: 117).

${ }^{3}$ El digger Peter Coyote lo describe así en el prólogo a Ringolevio, la "autobiografía" de Emmet Grogan: «The cultural propaganda machinery was in full swing. Rock Hudson and Doris Day were advertising America's consumer heaven to the rest of the world in sexless romps. "Ozzie and Harriet" and "Leave it to Beaver" offered bland television fantasies of family life, intimidating kids from mentioning their personal griefs, lest they be considered freaks. In real homes, people drank, fought bitterly, abused their children, had ulcers and worked themselves into early graves. Young people were pressured to study meaningless subject matter to enter college, to graduate and "make good" like the parents who were dying in front of them» (Coyote, 1990).
} 
-especialmente en los campus universitarios- inician su politización en el contexto de estas reivindicaciones.

La insuficiencia de las respuestas dadas por la izquierda tradicional a las demandas de transformación de esa sociedad conservadora y represiva favorecerá la eclosión de nuevas formas de cuestionamiento del poder. Las voces críticas se multiplican. El filósofo Herbert Marcuse, profesor en la también californiana Universidad de San Diego, comienza a plantear sus dudas de que sea la clase obrera la llamada a encabezar la lucha contra el sistema capitalista, en la medida que su potencial revolucionario ha quedado desactivado por una sociedad de consumo capaz de recuperar disidencias, absorber las críticas y alienar a la sociedad entera. La incorporación de las ideas del psicoanálisis al discurso marxista y, con ello, la estrecha vinculación del combate contra la explotación con la lucha contra la moralidad represiva vigente, le conducirán a plantear -con todas las dudas y precauciones que el asunto le merece- si acaso el nuevo sujeto de la deseada transformación debería tener en cuenta a los intelectuales, los estudiantes y el conjunto de subjetividades ligadas a reivindicaciones periféricas como la rebelión contra la moral dominante y la discriminación racial, sexual, etc. (Rodríguez García, 1997: 278). Es lo que en Europa están planteando los filósofos Michel Foucault o Gilles Deleuze: la superación de los esquemas de pensamiento tradicionales - la modernidad que nace con la Ilustraciónpara abrir la posibilidad de cuestionar no sólo al poder sino a lo que se presenta como su alternativa y que no es sino su repetición. Aparece un discurso sobre el poder que deconstruye la concepción tradicional y centra su atención en torno a los micropoderes, a las relaciones de poder realmente existentes a pequeña escala entre las personas, los grupos, las normas y las formas de pensar que se aceptan, se siguen y se imponen, la manera en que los deseos se expresan o se reprimen, cómo esos poderes y la sociedad entera trabajan para construir identidades manejables, operativas, útiles al sistema.

Estamos a las puertas de la revolución de 1968, acontecimiento que empieza a anunciarse en California, unos años antes -en 1964- cuando el Movimiento por la Libertad de Expresión -el FSM, Free Speech Movement- inicie sus protestas en la Universidad de Berkeley -al otro lado de la bahía de San Francisco-. Los jóvenes se movilizan contra aspectos "periféricos" de la estructura de dominación que perciben como una losa pesada, concretamente contra las limitaciones y prohibiciones puestas por las autoridades a las actividades en apoyo al Movimiento por los Derechos Civiles y en contra de la creciente implicación de los EE. UU. en la guerra del Vietnam. Pero estas reivindicaciones forman parte de una lucha de más amplio espectro. Después de detenciones y de semanas de huelga y sentadas, los estudiantes consiguen que sus 
exigencias se atiendan, pero la experiencia colectiva de la lucha contra un sistema que rechazan no va a darse por amortizada.

Vietnam será un punto de inflexión fundamental. En febrero de 1965 el presidente Lyndon Johnson ordena el inicio de los bombardeos sobre Vietnam. Enseguida comienza el envío de soldados y el reclutamiento de jóvenes para la guerra. 1965 es el año del asesinato del activista negro Malcolm X y de los disturbios raciales de Watts. 1965 es también el año del desembarco del LSD en San Francisco.

El principal responsable es un joven químico -August Owsley Stanley- hijo de un congresista, quien comienza a producirlo en su propio laboratorio de forma masiva, para ser luego distribuido con bastante generosidad. Las fiestas a base de ácido y marihuana y las manifestaciones contra la guerra transforman la vida cotidiana de la juventud. Se forman asambleas de estudiantes en muchas universidades y se queman cartillas de reclutamiento y banderas estadounidenses. Muchos jóvenes manifiestan su rechazo a la guerra vistiendo de manera anticonvencional, con ropas de colores, adornos más o menos vagamente inspirados en la estética de la India y dejándose el pelo largo en contraste con las cabezas rapadas de los militares: son los hippies. Sus hermanos mayores, gente del movimiento beatnik como Allen Gingsberg, Gary Snyder o Michael McClure, los respetados poetas de la corriente contracultural californiana de los 50, apoyan a los estudiantes y a los hippies, muchos de ellos recién llegados. Acuden atraídos por la vibrante nueva escena musical de la ciudad en general y por la contracultura psicodélica en particular. La mayoría de ellos se instalan en el barrio de Haight Ashbury -multicultural, barato y con muchas viviendas vacías-, que se convertirá en el centro de la escena alternativa de San Francisco.

El punto de arranque de la breve historia de los Diggers se encuentra en la Mime Troupe, una pequeña compañía de teatro alternativo, formada en el 62, que suele hacer sus representaciones en los parques de la ciudad ${ }^{4}$. Al frente está Ron Davis, cercano al movimiento de la Nueva Izquierda y que define sus planteamientos artísticos en un manifiesto que ha elaborado en mayo de ese mismo año de 1965. El nombre del texto, Guerrilla Theater -inspirado en el Che y en la revolución cubana-, se debe a Peter Berg, otro destacado activista de la Mime. Básicamente, lo que se propone es movilizar al teatro y a los artistas para promover la transformación política y social, en la línea de lo que Bertold Brecht propuso en los años treinta. Para que los fines de este teatro puedan llevarse a cabo, sus miembros -y cualquiera puede serlo- deben estar plenamente comprometidos. Quieren dejar atrás el concepto tradicional y burgués de teatro, con su rígida separación entre escenario y público. Evitan todo aquello que fomente la actitud

\footnotetext{
${ }^{4}$ Todas las referencias a los diggers, salvo que se indique lo contrario, están extraídas del libro de Alice Gaillard, Los Diggers. Revolución y contracultura en San Francisco (1966-1968).
} 
pasiva de su público: se trata, por el contrario, de que reaccione, que piense, que se transforme, no sólo que se divierta o esté entretenido un rato; es un teatro basado en la participación, en la improvisación y en la agitación.

En agosto del 65 la policía irrumpe en una actuación callejera de la Mime Troupe y se lleva detenido a Ron Davis entre los abucheos y protestas de la multitud. El alcalde había denegado el permiso para actuar en el parque acusando a la compañía de "obscenidad". El revuelo causado tiene el efecto de multiplicar el público de sus siguientes actuaciones. Se convierten así en un referente de la comunidad hippie y del movimiento alternativo en general, atrayendo en torno a ellos a cada vez mayor número de personas, algunas de los cuales se incorporan después a la compañía. Entre ellos, Peter Coyote -futuro actor del star system- y un tal Emmett Grogan, un chico de la calle neoyorquino de origen irlandés y carisma irresistible, con todo un historial de pequeños líos y que incluso afirma haber colaborado con el IRA.

Grogan empieza a colaborar con la Troupe, pero enseguida se cansa. Junto a un recién llegado, Billy Murcott, amigo de Grogan de los tiempos de Nueva York y con una roneotipia (especie de fotocopiadora) de los del SDS (Estudiantes por una Sociedad Democrática) que está guardada en local de ensayo de la Troupe, comienzan a escribir textos que esparcen por el barrio al modo de octavillas, para contrarrestar al detestado Oracle, el nuevo periódico de la comunidad psicodélica de Haight Ashbury y de su gurú Timothy Leary. Critican aquello en lo que se está convirtiendo el barrio, lleno de colgados y de tiendas donde se venden abalorios y ropas de estilo hippie junto con todo tipo de imaginería psicodélica. Con sus textos, Grogan y Murcott intentan «abrir los ojos a la gente de la calle, despertar su conciencia, ponerla en guardia contra la monumental estupidez implícitamente contenida en el psicodelismo trascendental» (Gaillard, 2010: 73).

En septiembre de 1966, con motivo del asesinato, a manos de la policía, de un chaval negro de dieciséis años en el barrio negro de San Francisco, se genera una semana de disturbios a la que las autoridades responden con un toque de queda. En sus octavillas, Grogan y Murcott animan a la gente a seguir haciendo una vida normal, desafiando las prohibiciones. Murcott, que acaba de leer un libro sobre los diggers británicos, los revolucionarios comunistas del siglo XVII, propone apropiarse del nombre para firmar sus octavillas, los Diggers Papers.

En ellos se critica el apoliticismo adocenado de los hippies, la brutalidad policial, el mercadeo creado en torno a la contracultura psicodélica; critican también a los de la Nueva Izquierda, promueven la subversión y alientan a pasar a la acción. Este pasar a la acción, verdadero núcleo de la propuesta digger, significa construir desde ya -now! es 
el mensaje que se lee en las pancartas de algunas de sus manifestaciones- un nuevo tipo de sociedad.

La revolución no consiste en lo macropolítico -las grandes ideas políticas o sociales, la toma del poder dentro del estado, la cual, en la práctica, es perpetuamente diferida-, sino en lo micropolítico, en la actuación en la vida cotidiana y en las redes de relaciones y las prácticas que realmente se producen. La sociedad está transformada cuando uno empieza a pensar y comportarse como si viviera ya en esa sociedad transformada. ¿En qué consistirá esa transformación? Básicamente en dos cosas: en asumir la total libertad individual y en destruir las relaciones basadas en la mercancía, el dinero y el consumo, es decir, precisamente, el tipo de relaciones que promueve el sistema capitalista.

Estas ideas de los diggers se materializan en la cultura free. 'Free', como es sabido, significa al mismo tiempo libre y gratis; se trata de desactivar la funcionalidad del dinero, deconstruir la mercancía, burlarse del fetiche. «Free because it’s tours», es su lema.

Una de sus primeras acciones, anunciada en las octavillas en las que desafían el toque de queda -y que se convertirá en paradigma de la subversión digger- será organizar repartos de comida gratis, a base de materiales "recuperados" -en realidad robados- en los grandes supermercados y en las aportaciones voluntarias. Pronto aparecerán por el barrio tiendas free, tiendas donde todo es gratis, apartamentos comunitarios con alojamiento gratuito -los crash pads, donde siempre había una habitación disponible para los recién llegados-, incluso un banco digger donde se distribuye gratuitamente dinero a quien lo solicita. Los diggers se manifiestan a través de sus octavillas, de la red de establecimientos libres que promueven y de periódicas representaciones públicas -más o menos "teatrales"- y que pueden adquirir la forma de manifestación, desfile, fiesta en un local cerrado, en la calle...

El teatro es territorio. [...] El Teatro Guerrilla pretende situar a la audiencia en un territorio liberado, crear actores de la vida (Life-actors). [...] Su objetivo es liberar el terreno ocupado por los guardianes del consumo y establecer territorios sin muros. Sus obras de teatro son cortavidrios para las ventanas del imperio (VV. AA., 1968).

El 17 de diciembre de 1966 los diggers organizan el desfile de La muerte del dinero y del renacimiento de Haight, una manifestación masiva en la que se quema dinero y se proclama festivamente el comienzo del fin de la vieja sociedad.

$\mathrm{Su}$ estrategia es un modo de arte social, en cierto manera asimilable a la escultura social (Soziale Plastik) que promueve el artista Joseph Beuys en Alemania por esos mismos años: 


\begin{abstract}
Así, una tienda de alimentación o una clínica o un restaurante que es gratis se convierten en una forma de arte social. Teatro sin tickets. Al margen del dinero y fuera de control. [...] Dejemos que las teorías económicas sigan a las realidades sociales (VV. AA., 1968).
\end{abstract}

Justo lo contrario de lo que se impone con claridad a comienzos del siglo XXI.

Pero la aventura digger no durará. De cara al exterior, 1967 es el año de la explosión hippie. Comienza con la celebración del Human Be-In, una multitudinaria fiesta-concierto en el parque del Golden Gate de San Francisco que reúne a decenas de miles de personas. Se reparten miles de cócteles de alcohol con LSD, hay conciertos, lecturas poéticas, pero la novedad no reside en la presencia de tales o cuales artistas sino que es «la multitud misma la que se convierte en protagonista» (Gaillard, 2010: 119), la multitud se convierte en acontecimiento.

Los diggers también están ahí, pero el éxito de la convocatoria no parece que les entusiasme. En la celebración masiva advierten la deriva espectacular del proceso, perciben en el horizonte el fracaso que supone que los participantes acaben reducidos a la mera actitud de espectadores pasivos. No todos lo ven igual: los comerciantes del negocio hippie, mientras tanto, se están frotando las manos. El impacto que tiene el evento atraerá a miles de jóvenes de todo el país. La invasión alcanzará su punto álgido en el verano -el Summer of love-, la apoteosis del San Francisco hippie. Es aquí donde surge un fenómeno tan típico del rock como lo serán los macroconciertos, con el festival de Monterey de junio de 1967 como referencia destacada, modelo del memorable festival de Woodstock celebrado dos años después en la otra punta del país, cerca de Nueva York. Al tiempo, la rebelión se transforma definitiva y literalmente en espectáculo para turistas, los cuales - por un módico precio- pueden recorrer en autobús Haight Ashbury haciendo fotos a los hippies y a los colgados y comprando souvenirs.

Los diggers, huyendo del protagonismo adquirido por su nombre, lo cambian por el de Free City Collective. Publican una guía para liberar ciudades. A finales de año -con San Francisco elevada a la condición de capital contracultural del mundoorganizan una gran concentración de repulsa contra aquello en lo que se está convirtiendo la ciudad bajo el lema La muerte del Hippie. Muchos hippies desencantados por la mercantilización y la banalización del proceso, abandonan la ciudad; se instalarán en comunas rurales donde poner en práctica sus ideas de libertad, ecología y vida comunitaria al margen de una sociedad que rechazan. Los diggers frecuentan por entonces el rancho Morning Star. Se trata de una comuna hippie cercana a la ciudad, que ha surgido a partir de la iniciativa de Lou Gottlieb, del grupo Limelitters y por Ramón Sender, hijo del escritor oscense y fundador del San Francisco Tape Music Center, del que se hablará más adelante. Esta comuna llegará a ser conocida 
como el "rancho digger" y, no por casualidad, el entonces gobernador de California y futuro presidente de EE. UU., Ronald Reagan manifestó su voluntad de cerrarla en varias ocasiones. Allí probablemente llegaran a coincidir Terry Riley y los diggers.

Aunque la marcha hacia las comunas, hacia el campo -o buscando una refundación de los principios culturales y vitales, el viaje a la India- señala el punto final, el fracaso del proyecto de transformación y de liberación de los espacios urbanos, los diggers mantendrán todavía un tiempo la actividad en la ciudad antes de disolverse definitivamente en junio del 68.

La escena musical de San Francisco se convierte en este periodo en la más innovadora del país, gracias -entre otros- a los conciertos que organiza Chet Helms, en el Avalon Ballroom o Bill Graham -el organizador del Human Be-In del Golden Gate Park- en el Fillmore Auditorium y a los festivales como el de Monterey en junio del 67. En las salas se proyectan diaporamas -grandes diapositivas con manchas móviles de colores- y light shows con luces estroboscópicas que contribuyen a crear, junto con el humo de la marihuana y los efluvios mentales del ácido, el ambiente propicio para la música ferozmente electrificada del rock psicodélico. Los carteles, con su imagen peculiar de gráficos licuosos y decoración abigarrada a cargo de ilustradores como Michael Bowen o Lee Conklin, contribuyen a difundir la estética psicodélica. Pero no es el único foco musical. Al otro lado de la bahía, en Oakland, junto a la Universidad de Berkeley y apenas a quince kilómetros del centro de la ciudad, el San Francisco Tape Music Center aglutina a una serie de pioneros de la música electrónica entre los que está Terry Riley, el segundo protagonista de este escrito.

Al principio se habló de una serie de sombras que se cernían sobre esta América radiante de los sesenta. El asesinato de Kennedy el 22 de noviembre de 1963 fue, como se ha recordado, una de ellas y podríamos afirmar que esta circunstancia tuvo un cierto efecto a $8.000 \mathrm{kms}$. de distancia y que ese cierto efecto bien pudo contribuir decisivamente al nacimiento del minimalismo musical. Lo contamos.

Terry Riley había nacido en Colfax, no muy lejos de San Francisco, en 1935 y realiza sus estudios en las dos grandes universidades del área de la Bahía, la S. F. State University y Berkeley. Es en esta última, asistiendo a clases de las materias de improvisación musical y música no occidental, donde conocería a una duradera amistad, LaMonte Young, pionero como el propio Riley del mínimal. Por entonces, ambos están investigando las posibilidades musicales de la mezcla del jazz más heterodoxo con la música clásica contemporánea -utilizando cintas magnetofónicas manipuladas- en un contexto de aplicación de la música a performances, happenings y danza. Así, el joven Riley colabora en San Francisco con la directora de danza contemporánea Anne Halprin y en Nueva York, con el artista Georges Maciunas y el grupo Fluxus. Después del breve 
paso por la costa este, se marcha a recorrer Europa. Visita España y Marruecos y acaba ganándose la vida tocando jazz al piano en los night clubs de las bases americanas en Europa. Está en París en noviembre del 63, cuando se produce el asesinato de Kennedy. Las bases cierran sus locales nocturnos indefinidamente en señal de luto y Riley se encuentra súbitamente sin trabajo y forzado a tomar decisiones respecto a su futuro. Tiene 28 años y regresa a California. Este regreso le hará replantearse toda su carrera musical y le decidirá a imprimirle un rumbo nuevo.

En San Francisco entra en contacto con el San Francisco Tape Music Center (SFTMC), un laboratorio sonoro de vanguardia dirigido por los músicos Morton Subotnick y Ramón Sender. En este espacio de innovación centrado en el desarrollo y aplicación de la electrónica a la creación musical y en la experimentación con todo tipo de recursos de estudio, es donde Terry Riley estrenará el 4 de noviembre del 64 la pieza que inaugura el minimalismo musical, In $C$. Según propia confesión, la idea le surge paseando por San Francisco, cuando está a punto de subir a un autobús ${ }^{5}$. No le costará mucho desarrollar la idea: en sólo un mes estará a punto para el definitivo estreno; son los mismos días en que la Universidad de Berkeley está en ebullición, con los estudiantes agrupados en el recién fundado Free Speech Movement.

Si se trata de cambiar las cosas y de buscar nuevos modos de vida, también puede plantearse entonces una manera distinta de producir la música. El hallazgo de Riley será el de crear una pieza sin una partitura cerrada, construida a través de la repetición de una serie de estructuras simples, abierta a la improvisación creativa de los intérpretes y con un concepto extremadamente flexible de ensemble.

Esa obra clave es In $C$. La partitura consiste en 53 patrones melódicos, bastante sencillos, para ser interpretados consecutivamente por un número indeterminado de músicos (siendo recomendable que sean unos 35, señala el compositor, «pero valen igualmente grupos más grandes y más pequeños»). La obra está escrita para cualquier combinación de instrumentos melódicos, incluidos sintetizadores y otros instrumentos amplificados, admitiéndose igualmente percusión, que debe improvisar «sin sobreponerse a los otros instrumentos». Los 53 patrones -interpretados en diferentes octavas según la decisión del músico- pueden ser repetidos tantas veces como se desee, sin una duración definida.

Las dificultades que este modelo de interpretación planteaba fueron solucionadas en los ensayos previos al estreno por un joven músico que participaba en ellos, Steve Reich, quien junto a otro neoyorquino, Philip Glass -con el que compartía un pequeño negocio de mudanzas y el oficio ocasional de taxista- se convertirá pronto en la máxima

\footnotetext{
${ }^{5}$ Si hubiera cogido un taxi es posible que los conductores fueran Steve Reich o Philip Glass, ya que ambos trabajaron brevemente como taxistas en San Francisco entre el 63 y el 64.
} 
figura de la música minimalista. Reich sugiere a Riley marcar el tempo con una nota constante de piano. Será el pulso, el latido rítmico que abre los compases iniciales de las interpretaciones de In $C$. Sobre él, como un fluir incesante de capas de sonido sobrepuestas que parecen deslizarse hipnóticamente hacia delante y hacia atrás, la música se va desarrollando, al mismo tiempo con un efecto repetitivo y, sin embargo, de constante cambio. La influencia del ambiente psicodélico de la ciudad es evidente. In $C$ es, en cierto modo, no solo la primera obra maestra de la música repetitiva sino también la primera pieza de lo que podríamos denominar música orquestal psicodélica; de hecho, en su presentación, se acompaña del mismo tipo de proyecciones y luces que se empleaban en las veladas psicodélicas del Fillmore o del Avalon. La primera grabación publicada de la obra es de 1970 y en ella destaca la presencia del extraordinario saxofonista Jon Hassell, heredero de muchas de las lecciones de Riley.

Si se examina con un poco de detenimiento el sentido de la obra, puede advertirse cómo In $C$, a través del lugar que da al intérprete, propone una conciliación entre la libertad del individuo y la construcción de lo común. La libertad queda expresada en el amplio margen de decisión e improvisación que tiene el músico, el cual puede realizar libremente pausas a lo largo de la ejecución puesto que no está sometido a ningún director de orquesta ni forzado por ninguna estructura de compases; el intérprete es dueño de su tiempo. En segundo lugar, la construcción de lo común -lo colectivo- se representa a través de la propia obra, sonando y desarrollándose de principio a fin, alcanzando una coherencia y una fuerza que es siempre distinta y única cada vez. A pesar de la peculiar (des)organización -si la interpretación no es fallida-, la escucha se convierte en una experiencia notablemente intensa y de una sobrecogedora belleza. Están documentadas en la red interpretaciones colectivas a cargo de músicos aficionados de todas las edades que han acudido al lugar del concierto -la propia calle en ocasiones- con sus respectivos instrumentos formando una auténtica multitudo, una heterogénea mezcla de gente reunida para llevar a cabo la ejecución de la obra, de un modo que es muy difícil -si no imposible- plantear para la mayoría de las creaciones artísticas del signo que sean.

Riley escribirá de In $C$ : «Esta música nos ha enseñado un nuevo sentido del tiempo», enseñanza análoga a la percepción ampliada que busca la experimentación con las drogas o la ruptura con los ritmos prefabricados de la vida sometida. Esta investigación de la relación música y tiempo se afirma igualmente en los All-Night Concerts que Riley realiza a partir de 1967. En estos conciertos, Riley se presenta con un viejo órgano, un saxofón y cintas magnetofónicas con las que va grabando fragmentos para -acto seguido-, reproducirlos cíclicamente. Con ello, crea sucesivas capas melódicas sobre las que situar los fraseos repetitivos y las improvisaciones. En los 
conciertos la música fluye horas y horas sin interrupción y concluyen al amanecer. El público, a veces formado por familias enteras, escucha la música bailando bajo las luces psicodélicas o recostado -algunos durmiendo- entre los almohadones, anticipando los futuros ambientes del chill out.

La Materia del Tiempo [nombre de la escultura de Richard Serra instalada en el Museo Guggenheim de Bilbao] está basada en la idea de la multiplicidad de temporalidades escindidas en capas. La duración - no el tiempo literal del reloj- es el principio organizativo principal que dirige la obra. El tiempo de la experiencia puede ser rápido o lento, lo que depende enteramente del movimiento del cuerpo. La escucha de la música [...] es tiempo subjetivo y comparable al tiempo de observación de mi trabajo (Serra, 2005).

Las palabras son del artista, también de San Francisco, Richard Serra y, aunque se refieren a Steve Reich -quien durante estos años se ganó la vida trabajando un breve periodo como asistente del escultor-, bien podrían valer para su maestro Terry Riley. Serra no cita en este texto a Riley porque está hablando del grupo de artistas que coinciden en Nueva York a finales de los sesenta y principios de los setenta. En todo caso podríamos añadir que Riley experimentó una cierta marginación debido a que sus líneas de investigación musical durante los años setenta fueron diferentes a las del núcleo duro del minimalismo, básicamente Philip Glass y Steve Reich. Hay que recordar que Terry Riley a finales de los sesenta deriva sus pasos hacia una música electrónica repetitiva de estética psicodélica dejando de lado, en principio, la escritura musical para formato clásico. A rainbow in curved air, de 1969, es su obra maestra en este sentido. Poco después se convertirá en discípulo de Pandit Pran Nath, maestro de la música clásica hindú, y viajará en numerosas ocasiones a la India, siguiendo la dirección que muchos hippies tomaban a comienzos de los setenta, la búsqueda de las fuentes de la espiritualidad oriental como modo de superar el camino sin salida de la decadencia de la sociedad de consumo occidental. No está claro hasta qué punto interesaron a Riley estos aspectos, pero es obvio que la estructura repetitiva, deslizante, cíclica de las ragas indias, la sonoridad envolvente e hipnótica de su música tradicional y su flexibilidad para la improvisación integrada en complejas estructuras, era un territorio de estudio insoslayable en la dirección del camino musical iniciado por el compositor californiano con In $C$. A partir de los ochenta y muy vinculado a la colaboración de Riley con el Kronos Quartet, retomará la composición de piezas para orquesta convencional de tradición occidental.

Volvamos al texto de Richard Serra. Se trata de una alocución en honor de Steve Reich, leída con motivo de la entrega de un galardón artístico (el MacDowell Medal Award) al músico neoyorquino en 2005. En ella, como se ha dicho, el escultor cita a otros artistas que, según su consideración, contribuyeron a la apertura en aquellos 
decisivos años de nuevos caminos al arte; entre ellos destaca a Bruce Nauman, el último protagonista de este artículo.

No sabemos hasta qué punto Nauman tuvo un contacto directo con los diggers o con las actividades que se estaban realizando en Haight Ashbury, pero es muy posible que sus caminos se cruzasen con alguna frecuencia: su amigo Steve Reich compone música para la San Francisco Mime Troupe, concretamente para la representación de la obra de Alfred Jarry Ubú Rey, en la que Reich toca en directo con su ensemble. No es descabellado imaginar la presencia de Nauman en el evento. Al estreno de la obra, el 11 de diciembre de 1963, quien sí que asiste, por cierto, es Terry Riley, el cual -para sorpresa de Reich que lo había localizado entre el público- se marcha a mitad de concierto. Al día siguiente, Reich, acude a buscar a Riley al estudio que éste tiene en un garaje. Se supone que estaba intrigado por conocer las razones por las que se había ido. Desconocemos cuáles fueron, pero sí sabemos -por testimonio del propio Reich- que así es como los dos grandes músicos se conocieron.

En una extensa conversación con Michele De Angelus, disponible en la red (De Angelus, 1980), Nauman comenta a la entrevistadora que, a pesar de reconocer la influencia que la música de Riley tiene sobre su obra, no llegó a conocerlo personalmente pero que en esta época lo vio en directo una o dos veces. Es muy probable que una de ellas fuera el estreno de $\operatorname{In} C$, en el que, tal y como se ha comentado, actuó su colega Steve Reich. Nauman, por otro lado, poseía una cierta formación musical y tocaba el bajo en un grupo aficionado de jazz; la música, aún más que los predecibles referentes en las artes plásticas - de cuya tradición pretendía liberarse- es en ese momento una referencia esencial para su investigación.

Su análisis parte, de hecho, de la reflexión en torno a cómo crean su música Riley, Reich, Philip Glass o LaMonte Young, logros que podrían resumirse en la idea de una «multiplicidad de temporalidades escindidas en capas» a la que aludía Serra. Le interesa especialmente, esta vez en sus propias palabras,

la percepción de estructura y tiempo, de cosas que continúan. La idea de LaMonte -prosigue Nauman- de que la música circule indefinidamente y que la actuación sea continua y siempre disponible. Que no haya ni un principio ni un fin (De Angelus, 1980).

Es el concepto que -se ha visto- subyace a la actividad de los diggers, una performance sin principio ni final que se confunde con la vida; una actividad creativa $-\mathrm{y}$ por lo tanto transformadora- para la que no sirven los marcos de referencia artísticos tradicionales. Es ésta también, desde luego, la idea que está presente en la música de Riley y, paradigmáticamente, en sus All-Night Concerts, donde la posibilidad de asistir al "concierto" de la manera usual está prácticamente descartada. La gente entra y sale 
del lugar del concierto, habla, come, alucina o duerme, viene - "tarde"- y se va - "antes"- sin llegar a "perderse nada", porque el desarrollo de la pieza a base de repeticiones e improvisación es totalmente fluido y abierto.

Me interesa también [de este tipo de música] la percepción de que no hay progresión -comenta Nauman en la misma entrevista-, simplemente sigue y sigue hasta que tú eliges parar. A mí realmente me gustaba la idea de una performance o cinta de video que durase bastante más que una película, o una película que se desarrollase en repeticiones circulares (loops) y cosas así. Tienes que repetir una acción y, a la vez, debido a la larga duración, cometes errores, ocurren imprevistos, cambios, te vas cansando y pasan todo tipo de cosas, así que se produce una cierta tensión que puedes explorar cuando empiezas a entender cómo funciona. Y muchas de mis videocreaciones eran sobre esto [...]. La relación del espectador cuando algo tiene comienzo, medio y final es totalmente diferente (De Angelus, 1980).

Esta concepción de temporalidad abierta, de incompletitud, será uno de los recursos estéticos recurrentes de Nauman para sus videos e instalaciones.

Bruce Nauman no había nacido en California pero su carrera va a estar estrechamente ligada a ella, en particular a la ciudad que nos ocupa, San Francisco, donde reside, estudia y ejerce de profesor de arte $^{6}$ en estos años cruciales de la segunda década de los sesenta. Su primera exposición en solitario tiene lugar en la ciudad de Los Angeles, entre mayo y junio del 66, en la Nicholas Wilder Gallery. Tiene 28 años, como Riley cuando estrena In $C$.

Es en San Francisco donde Nauman establece lo básico de su vocabulario artístico. Ha abandonado la pintura tradicional e investiga con nuevos materiales. Es uno de los primeros en trabajar con fibra de vidrio o con tubos de neón. Pero, más allá del empleo de unos materiales u otros, su interés se centra en lo que se podría denominar las condiciones de la experiencia estética, tratando de responder a la pregunta de qué objetos, qué espacios podemos percibir como estéticos y cómo lo hacemos. Ese es el objetivo de sus esculturas, de sus performances grabadas, de sus videocreaciones, de sus obras construidas a base de sonidos o de palabras, etc.

De esta época son muchas las piezas de videoarte de Nauman que resultan accesibles en la red. Ellas nos permiten reconstruir, junto con las imágenes de otro tipo de obras, las preocupaciones estéticas del autor en estos inicios de su carrera.

Cualquiera que sea el formato, un rasgo característico de la obra de Nauman, muy conectado con el ambiente de rechazo a los valores constituidos, es su indiferencia frente al acabado, desentendiéndose de la forma final. Para él lo principal es la idea -aunque como se ha dicho, no en cuanto origen o inicio del proceso, sino como efecto

\footnotetext{
${ }^{6}$ Nauman trabaja como profesor entre el 1966 y el 68 en el San Francisco Art Institute.
} 
de un estado intermedio de elaboración-, abriendo el camino a lo que será el arte conceptual.

En su condición de aparente inacabamiento, los objetos de Nauman -lo mismo que las imágenes carentes de narratividad de sus vídeos, que parecen jugar con la idea del tedio- lo tienen muy complicado para captar la atención. Así, una constante que aflora en su obra es la de unas imágenes que, perdidas en la vorágine objetual de la detestada sociedad de consumo, buscan silenciosa y, tal vez, desesperadamente llamar la atención sobre sí mismas. No por casualidad el texto en el que se recopilan gran parte de sus escritos lleva por título Please pay attention please (Nauman, 2005).

Un ejemplo de este tipo de procedimientos estéticos serían sus obras de neón: construye con tubos luminosos de colores, palabras, conceptos y frases, más o menos filosóficas, más o menos cercanas al cliché, o a veces al juego de palabras o incluso al chiste malo $^{7}$. En 1967, produce una de sus obras más representativas y más reproducidas, El artista ayuda al mundo revelando verdades místicas. La obra consiste en una espiral de neón roja enmarcando el texto que le da título, hecho en tubo luminoso azul. La fuente de inspiración, tal y como confiesa el propio autor, es un reclamo publicitario de cerveza habitual en los bares. El escultor minimalista Sol LeWitt acababa de publicar en la revista Artforum, en su número de junio, lo que puede considerarse su manifiesto artístico, Párrafos sobre arte conceptual, que se iniciaba con la frase «los artistas conceptuales son más místicos que racionalistas». Recuperando la alusión de LeWitt, formulada para un público especializado en una revista de arte y trasladándola -en una especie de inversión del procedimiento del Pop art- a un formato vulgar -el anuncio de neón-, Nauman parece aludir a sus dudas sobre cuál es el papel del artista plástico en un mundo que necesita transformarse. Son los días en que la ciudad se convierte en un centro de agitación global y la alusión al lugar del artista no puede sino remitirse a la revolución que ocurre a su alrededor. En cualquier caso, la reflexión parece teñida de melancolía o de una distancia irónica muy duchampiana; se sabe que Nauman está presente el día de la macroconcentración festiva y contestataria del Human Be-In de San Francisco en enero del 67, meses antes de elaborar la pieza. Allí escucha a Leary formular el lema lisérgico del Turn on, Tune in, Drop out -«Colócate (con un ácido), sintoniza (con tu propia energía), escapa (de tu identidad)»-; allí está Gingsberg recitando mantras y allí tocan los Grateful Dead y los Jefferson Airplane, mientras el white-lightening, el cóctel con LSD cortesía de Owsley Stanley, circula masivamente entre la muchedumbre. Son condiciones materiales y objetivas

\footnotetext{
${ }^{7}$ El crítico Robert Hughes se ha quejado de que Nauman explota «todo aquello que puede ser irritante: estética agro, solipsismo, tensión, torpeza y chistes malos» (Gayford, 2004). A este respecto puede citarse Violin tuned D.E.A.D (Violín afinado Re-Mi-La-Re, según la notación anglosajona, pero también Violin afinado MUERTO, video, 1968) y otras obras posteriores como Clown Torture (Vídeo, 1987).
} 
específicas que seguramente no estén desconectadas de su reflexión sobre las palabras de LeWitt.

Es ciertamente probable que, en aquellas primeras macroconcentraciones de gente, Nauman reflexionase sobre el propio lugar, sobre el espacio reservado al individuo entre la multitud. Su obra está llena de objetos de percepción que tienen muy complicada su visibilidad en un contexto de saturación y multiplicación, pero la cuestión estética se juega precisamente en ser capaces de prestarles atención, en dotar a la mirada de nuevas destrezas. Es la percepción de lo microsocial, micropolítico o microestético, de lo capilar, de lo que irriga el horizonte perceptivo.

Se trata de deconstruir la invisibilidad en un mundo espectacular, en un mundo de sobredosis de estímulos visuales. El cuerpo filmado retorciéndose la piel, estirándola y plegándola de Pinchneck (Vídeo, 1968) es una llamada de atención sobre la carnalidad, la materialidad de lo que se suele tender a entender como una construcción abstracta más, el propio cuerpo. El autor, filmándose recorriendo -más o menos cuidadosamenteel perímetro de un cuadro dibujado en el suelo (Walking in an Exaggerated Manner around the Perimeter of a Square, 1967), repite el mismo esquema, en este caso, llamar la atención sobre un movimiento-en-sí, a-significante, movimiento que si fuera en círculos o si fuera azaroso pasaría desapercibido en cuanto movimiento pues remitiría a alguna exterioridad-significado, se invisibilizaría impregnándose de connotaciones, simbolismos, perdería su precisión. Limitándose a recorrer un trazado que impide cualquier especulación estética o simbólica, concentra la atención sobre lo previamente desposeído de presencia y visibilidad. En la misma línea, Lighted Performance Box, de 1969: es una columna de aluminio de sección cuadrada de dos metros de altura; una bombilla oculta, situada en la zona superior irradia hacia el techo. Sin esta luz escondida en el interior, el objeto, la escultura, permanecería invisible, camuflada en su inconsistencia, como un elemento arquitectónico más, destinado tal vez a recubrir cables, como una especie de canalización de aire acondicionado o un anónimo pedestal.

Más específicamente conectado con el contexto hippie parece su obra Una rosa no tiene dientes (A Rose Has No Teeth, 1968), que consiste en una chapa de plomo con la frase que le da título grabada. El texto procede de las Investigaciones Filosóficas de Wittgenstein, uno de los autores, junto con Beckett, que más frecuentemente cita Nauman. La idea original era clavarla en un árbol y que la corteza la fuera deformando a medida que el árbol creciese. Es un concepto extraño de escultura monumental para exteriores. La naturaleza -el árbol, la "rosa" evocada por la placa- a pesar de "no tener dientes", lo que parece aludir a su carácter no agresivo o depredador, se impone por su fuerza interna al duro metal, al plomo forjado por el ser humano. Es una potencia 
ilimitada y paciente que no teme al poder de la técnica y a su violencia. La alusión a la flor -en San Francisco, en 1966- no puede ser más obvia.

Un último procedimiento artístico que Nauman pone en marcha en este periodo $-\mathrm{y}$ que igualmente tendrá un largo recorrido en su obra- es el de la creación de espacios artísticos expresivos, que -al igual que sus objetos reclamando la atención en medio de la sobreabundancia de imágenes- buscan también abandonar su estado inerte, invisible o neutro y convertirse en interlocutores del sujeto que los habita o recorre. En 1969 produce su primera escultura/instalación de corredor. Consiste en dos muros paralelos, formando un estrecho pasillo de sólo medio metro de ancho y seis de profundidad. Cerrada en la parte superior por tubos fluorescentes que lo iluminan, sus casi dos metros y medio de altura contribuyen a dar una intensa sensación de claustrofobia al visitante que lo observa. En su instalación de 1969 Get Out of my Mind, Get Out of This Room, una habitación vacía esconde unos altavoces que susurran, gritan y exhortan alternativamente al visitante con las palabras que dan título a la obra: «Sal de mi mente, sal fuera de esta habitación, sal de mi mente, sal fuera de esta habitación, sal de mi mente, sal fuera de esta habitación...», sin principio ni fin. De nuevo un espacio que busca llamar la atención a través de una cierta tensión o agresividad. La ficción del espacio neutro se rompe; la habitación -como en una película de terror-cobra vida. Pero también es una manera velada de aludir a formas de subjetivación que exceden el "yo" -la identidad con la que nos identificamos para poder responder con eficacia a las exigencias de la vida en sociedad-. El individuo no se reduce a eso, es la primera lección que se obtiene cuando se abren las puertas de la percepción. Y no es imprescindible el acid-trip. Las vivencias, especialmente las que van acompañadas de una cierta intensidad, nos enlazan indisolublemente con personas, lugares, sonidos, afectos, perceptos, conceptos, estratos heterogéneos, en los que ese yo no es más que una parte y no siempre la parte principal, hegemónica. Cada persona se compone con espacios, con su propia memoria -llena de lugares asociados a sentimientos, reconfortantes u hostiles-; es en esa realidad, en esa cotidianeidad, -es verdad que muchas veces invisible- donde los espacios nos hablan. Y esa es también la lección de Nauman.

Una última obra sirve como ejemplo de la condición reivindicativa, ecológica e irónica, del carácter -al mismo tiempo- autoafirmativo, tautológico y fútil que comparten tantas creaciones de Nauman. Se trata de Leave the Land Alone, concebido en 1969, pero sólo llevado a cabo cuarenta años después. La obra consiste en lo siguiente: varios aviones escriben con grandes letras de humo sobre el límpido azul del cielo californiano «Dejad la tierra en paz». 
248 Tropelías. Revista de Teoría de la Literatura y Literatura Comparada, 18 (2012)

Óskar Díez

\section{Bibliografía}

AUPING, M. (2007): "Interview with Bruce Nauman", B. N. 30 Years: Interviews and Outtakes, en http://www.speronewestwater.com/cgibin/iowa/articles/record.html?record=650 (última consulta, 1-7-2011).

COYOTE, P. (1990): “Introduction to Ringolevio: A Life Played for Keeps by Emmett Grogan", en http://www.petercoyote.com/ringo.html (última consulta, 1-7-2011).

DE ANGELUS, M. D. (1980): “Oral History Interview Bruce Nauman, 1980 May 2730", Archives of American Art, Smithsonian Institution, en http://www.aaa.si.edu/collections/interviews/oral-history-interview-bruce-nauman$\underline{12538}$ (última consulta, 1-7-2011).

GAYFORD, M. (2004): "Sculpture for the ears", The Daily Telegraph (12-10-2004), en http://www.speronewestwater.com/cgi-bin/iowa/articles/record.html?record=310 (última consulta, 1-7-2011).

GAILlARD, A. (2010): Los Diggers. Revolución y contracultura en San Francisco (1966-1968). Trad. de Diego L. Sanromán. Logroño, Pepitas de calabaza.

GROSS, J. (1997): "Interview with Terry Riley", Perfect Sound Forever, en http://www.furious.com/perfect/terryriley.html (última consulta, 1-7-2011).

HAGGERTY, A. (1992): "Terry Riley, ambient guru. Interview with T. R.", en http://www.qaswa.com/qaswa_v1/rhythmos/terry.html (última consulta, 1-7-2011).

JÍMENEZ, P. (2000): "Rock'n Roll suicide I”, Riff Raff, 12.

NAUMAN, B. (2005): Please Pay Attention Please: Bruce Nauman's Words: Writings and Interviews. Ed. de J. Kranyak. Cambrigde, MA/Londres, The Mit Press.

RODRÍGUEZ GARCÍA, J. L. (1997): La palabra y la espada, Madrid, Talasa.

SERRA, R. (2005): "Text written for Macdowell Medal Award Ceremony for Steve Reich", en http://www.stevereich.com/articles/Richard_Serra.html (última consulta, 1-7-2011).

STORR, R. (2009): "Bruce Nauman: The man who would not be king", en http://www.speronewestwater.com/cgi-bin/iowa/articles/record.html?record=665 (última consulta, 1-7-2011).

TUCKER, M. S. (2007): “At Play in the Fields of the Mind: 1968-1986”, Perfect Sound Forever, en http://www.furious.com/perfect/terryriley2.html (última consulta, 1-72011).

VÁZQUEZ GÓMEZ, P. (2002): "Nuevas tendencias: el minimalismo”, Filomúsica, 25, en http://www.filomusica.com/filo25/grana.html (última consulta, 1-7-2011).

VV. AA. (1968): "Trip Without a Ticket" (1966-67), The Digger Papers, en http://sniggle.net/Manifesti/ticket.php (última consulta, 1-7-2011). 